\title{
Educação e preservação de sítios arqueológicos
}

André Cabral Honor*

RESUMO

Este trabalho faz parte do projeto de monitoria desenvolvido na disciplina "PréHistória", do Curso de Graduação em História da Universidade Federal da Paraiba, durante os períodos letivos 2004.1 e 2004.2, sob orientação do Prof. Dr. Ricardo Pinto de Medeiros. Tem como principal objetivo desenvolver uma possibilidade metodológica de educação patrimonial, voltada especificamente para a preservação do patrimônio arqueológico. Almeja-se que o aluno possa se identificar com esse tipo de bem, tornando-se assim vetor multiplicador da consciência de preservação, sendo despertado para a importância da História na construção de uma sociedade sustentável, que permita às gerações futuras o acesso a conhecimento nas suas mais variadas formas, construindo desta forma uma identidade social.

Palavras-chave: Patrimônio, Arqueologia, Metodologia, Educação patrimonial

Com o advento da modernidade, a revalorização do novo e o aumento da velocidade nas mudanças ocorridas na sociedade, acirram-se os debates sobre a importância da preservação do patrimônio histórico, sua conciliação com a idéia de progresso, e a participação da sociedade em sua conservação através do desenvolvimento de metodologias que lidem com a educação patrimonial.

Tendo em vista essas colocações, procuramos discutir uma proposta de metodologia de educação patrimonial voltada para a preservação de sítios arqueológicos, uma vez que estes enfrentam problemas diferenciados de

\footnotetext{
* Mestrando em História Programa de Pós-Graduação em História - Universidade Federal da Paraíba (PPGH/UFPB) - e-mail: falanariga@bol.com.br - Duas versões preliminares deste trabalho foram apresentadas: no $8^{\circ} \mathrm{Cidade}$ revelada - Encontro de Patrimônio Histórico, Arquitetura e Turismo, promovido pela Fudação Cultural de Itajaí; e, no XXIII Simpósio Nacional de História - História: Guerra e Paz, promovido pela Associação Nacional de História - ANPUH, realizado na Universidade Estadual de Londrina, entre 17 e 22 de julho de 2005.
} 
degradacçĩo do patrimônio histórico arquitetônico, integrado ou imaterial. Isso não significa que inexistam pontos de convergência entre as dificuldades encontradas em suas respectivas preservações. Os fatores de degradação, muitas veres, são os mesmos: o vandalismo, por exemplo, é um dos mais graves, e é justamente para prevenir tais agressões que as metodologias educacionais se fazem indispensáveis para a preservação destes bens.

Patrinıonio, palavra que vem do latim patrimonium, é todo bem ou conjunto de bens herdado de gerações anteriores que são indispensáveis na identificação da sociedade com sua história e cultura devendo, portanto, ser preservados. Infelizmente, esta consciência demorou a ser "reconhecida" pelos órgãos governamentais ${ }^{2}$, os quais nem sempre adotaram as medidas mais eficazes, cometendo inclusive equívocos. Na maioria das vezes, a população local fica alheia a debate sobre a preservação devido à ausência de uma política de educação patrimonial. Desta forma, explica-se em parte, por que certas ações de preservação encontram resistência na sociedade que vê o patrimônio como uma barreira ao desenvolvimento local.

Neste contexto, o patrimônio arqueológico sofreu uma degradação ainda maior no Brasil, visto que a lei federal de proteção aos sítios arqueológicos data de 1961, mais de vinte e cinco anos após a criação do SPHAN. Até essa data, era comum que obras públicas e privadas résultassem na destruição parcial ou completa de sítios

Segundo Edna June MORLEY (1999, p. 129), são três as principais causas de destruição do patrimônio arqueológico: as obras de grande porte nas áreas com potencial arqueológico, o aproveitamento econômico das áreas de interesse arqueológico e o vandalismo. Leis severas e fiscalização eficiente são fundamentais para barrar tais fatores, porém essas não conseguem impedir a destruição dos sítios por si só; tais medidas devem ser seguidas por metodologias educacionais ligadas à preservação do patrimônio, que sejam aplicadas à população moradora das áreas com potencial arqueológico, para que a populaação passe a fazer parte da solução e não mais do problema tornandose agente de defesa de tais bens, barateando, ainda, os custos de preservação dos mesmos.

Antes de qualquer passo é imprescindível que o professor procure analisar

2 Mais precisamente em 1937, com a criação do SPHAN, atual IPHAN. 
o conhecimento prévio de seus alunos a respeito do que seja o patrimônio e sua preservação. Baseando-se no que for coletado da vivência dos alunos, o professor deve debater e discutir o assunto em sala de aula, para que os estudantes tenham um aprofundamento maior da matéria e da sua importância nos dias atuais. Somente após esse estudo inicial, o professor os convidará a "descobrir" um patrimônio histórico em sua cidade. Na metodologia aqui discutida, a inclusão de temas específicos na sala de aula relacionados à arqueologia é de vital importância para o bom andamento do processo de educação. Textos e imagens podem ser, inclusive, ferramentas motivadoras de debates sobre a extensão das ciências e conhecimentos que a arqueologia envolve. Feitos estes estudos iniciais, os alunos estarão aptos a acompanhar com maior interesse as etapas da metodologia de educação patrimonial a ser aplicada pelo professor.

A metodologia que será descrita a seguir tem como base fundamental o manual do projeto Tesouros do Brasil (Tesouros do Brasil, 2004), porém com as devidas adaptações para que estas se encaixem no tema proposto. Trata-se de uma metodologia bastante eficaz na sala de aula, mas que, a nosso ver pode ser estendida para atingir toda a população local e não só os alunos da escola.

A primeira etapa a ser conduzida é a observação: nela os alunos irão identificar os bens a serem estudados. Nesse momento eles podem tanto usufruir de pesquisas já realizadas para saber onde se encontram os sítios arqueológicos - por isso a importância da difusão, em termos acessíveis aos leigos, das pesquisas e achados em áreas arqueológicas - ou realizar uma pesquisa própria com a população local, para saber onde possam encontrar lugares com potencial arqueológico. À primeira vista, parece difícil localizar tais bens, mas a própria comunidade pode ajudar caso a pesquisa seja bem orientada3. Perguntas dirigidas à população sobre histórias de lugares assombrados (por terem sido cemitérios indígenas), locais onde se encontram as "pedras de raio", (na verdade machadinhas indígenas), pinturas ou gravuras rupestres que não foram catalogadas ou, locais onde fósseis são facilmente localizados; podem lhes proporcionar boas pistas sobre a localização de possíveis sítios arqueológicos. Toda essa etapa tem o objetivo de definir um sítio a ser estudado pelos alunos.

\footnotetext{
3 Apesar de prever essa possibilidade, o professor deve estar atento aos limites que o seu conhecimento impõe, não devendo, em hipótese alguma, ultrapassar o bom senso, através, até mesmo, da invenção de lugares a serem pesquisados.
} 
A segunda etapa do processo é o registro, na qual os alunos elaborarão um arquivo contendo todas as informações que foram possíveis de serem observadas a respeito do local. Este é o momento ideal para que os alunos visitem o sítio proposto, alvo do estudo, lembrando que o professor deve alertar os alunos para não interferirem no local, visando deixá-lo o mais livre possível da intervenção humana atual, pois a manipulação do ambiente poderá afetar futuros estudos arqueológicos no local. Nessa etapa, vários recursos poderão ser utilizados pelos alunos, desde anotações descritivas sobre o que foi visto, passando pela confecção de desenhos e mapas da localidade do sítio, até a utilização de filmagens e recursos fotográficos. Também é recomendável o professor trabalhar com os recursos que lhe são disponíveis, transformando-os em ferramentas de pesquisa. Para isso ele deve procurar a colaboração dos professores das outras disciplinas, que podem lhe ajudar com idéias que venham a substituir a escassez de material, como desafiar os alunos a fazerem suas próprias máquinas fotográficas com latinhas de metal. 0 registro é de vital importância para o processo de educação, pois visa fixar e, como o próprio termo define, registrar o conhecimento que foi apreendido, possibilitando a sua utilização nas etapas seguintes.

A terceira etapa é a que chamamos de exploração. Aqui os alunos irão pesquisar os dados coletados no registro e aprofundarão seus conhecimentos. A intenção desta etapa é desenvolver o debate crítico dos alunos através da construção da história do bem estudado. Para isso o aluno, sempre com a orientação do professor, irá pesquisar, nas diversas fontes disponíveis, todos os dados que se refiram, ou pelo menos, que se remetam ao sítio. Lugares como bibliotecas, arquivos e internet, além de possuírem material com um valor teórico relevante, servirão também de exemplo para que os alunos percebam os percalços existentes em uma pesquisa e aprendam a superar estes obstáculos descobrindo assim o prazer de achar a informação almejada. Algumas das entrevistas realizadas na observação podem ser retomadas, e até mesmo refeitas, com o intuito de aprofundarem os conhecimentos já apreendidos.

Um fator importante na realização da pesquisa consiste na elaboração prévia de uma problematização do tema. Uma boa idéia é que cada aluno, ou grupo de alunos, saia com um questionamento diferente como: Quais foram os povos que habitaram aquele local? Quando aquele local começou a ser 
urbanizado? Existia ou ainda existe algum interesse econômico naquela área? Qual o motivo do deslocamento desses povos? Ainda existem remanescentes deles naquela área? Que tipo de vestígios pode-se encontrar naquele local? A quem pertence atualmente o local a ser pesquisado?

Outras perguntas podem ser formuladas, sempre procurando estabelecer um contato entre os alunos e o sítio arqueológico em pesquisa. Após todo esse estudo estará criada a ponte necessária para o passo seguinte da metodologia.

A próxima etapa aqui proposta é chamada de apropriação. Neste estágio os alunos utilizarão os conteúdos que foram apreendidos nas etapas anteriores para desenvolver um trabalho que tenha como tema o sítio arqueológico estudado. A idéia é que eles fiquem o mais à vontade possível para desenvolver uma releitura do local estudado, que pode se dar através de um trabalho acadêmico ou por alguma espécie de expressão artística, como pintura, escultura, desenho, fotografia, peças teatrais, composições, poemas, etc. Esta etapa é primordial para que o sítio arqueológico seja inserido na história pessoal de cada aluno, estabelecendo assim uma conexão entre o mesmo e o sítio arqueológico estudado despertando a idéia de preservação do local.

A última etapa proposta consiste na sensibilização. A metodologia ultrapassará a sala de aula e atingirá a comunidade à qual o sítio arqueológico está inserido. 0 professor reunirá todos os trabalhos realizados na etapa anterior e preparará uma exposição aberta à comunidade para que esta possa ver (e quem sabe até mesmo interagir) com a pesquisa realizada pelos alunos. A exposição poderá acontecer no próprio colégio; o que não impede que os alunos busquem apoio em outras instituições, para que ela também possa acontecer nos mais variados locais, podendo-se realizar, quem sabe, até mesmo, uma exposição itinerante em pontos estratégicos da cidade, incluindo espaços abertos, como praças e parques públicos. 0 intuito desta etapa é fazer com que a comunidade tome conhecimento da existência do sítio arqueológico e do caminho educacional percorrido pelos alunos envolvidos, sensibilizando a população para a importância de sua preservação, iniciando assim um processo de inclusão da mesma na história do local, tornando-a parte ativa na preservação do referido bem.

Como toda metodologia educacional, esta também não se encontra isenta de falhas, e pode - na verdade, deve - ser modificada para que melhor se 
adeqüe à cada contexto. Os resultados dependem muito da dedicação do professor ao projeto, do interesse dos alunos e da criatividade dos envolvidos. É importante que fique claro que o professor não pode ter a ilusão de que a metodologia conseguirá atingir a todos os alunos, nem que essa é a solução definitiva para a preservação do patrimônio arqueológico. Porém isso não diminui a urgência e a necessidade de sua aplicação, pois é através da educação patrimonial que será plantada a semente para que as fontes sejam preservadas em seu estágio mais rudimentar, permitindo às gerações futuras formular suas próprias conclusões, construindo uma história que servirá de fator transformador da sociedade.

Encerro, assim, com as palavras ouvidas pelo autor, quando em visita aos locais onde se encontravam os antigos engenhos coloniais da várzea do Rio Paraiba, palavras proferidas pela Sra. Maria do Socorro Nascimento, analfabeta, lavradora, residente ao lado das ruínas do antigo engenho de Massangana, que ao indignar-se e emocionar-se com o estado da edificação, resumiu a importância da história para a vida: "É preciso contar a história de Massangana, pois um povo sem história não é gente. Não pode ser gente".

\section{Referências}

CHOAY, Françoise. A alegoria do patrimônio. Tradução de Luciano Vieira Machado. São Paulo: Editora da UNESP, 2001.

FENELON, Dea Ribeiro. Políticas culturais e patrimônio histórico. In: O direito à memória: patrimônio histórico e cidadania São Paulo: Secretaria Municipal de Cultura/ Departamento do Patrimônio Histórico, 1992.

MORLEY, Edna June. Como preservar os sítios arqueológicos brasileiros. In: TENÓRIO, Maria Cristina (org.). Pré-bistória da Terra Brasilis. Rio de Janeiro: Editora da UFRJ, 1999.

HORTA, Maria de Lourdes Parreiras; GRUNBERG, Evelina \& MONTEIRO, Adriane Queiroz. Guia básico de educação patrimonial. Brasília: Instituto do Patrimônio Histórico e Artístico Nacional (IPHAN), 1999.

PROUS, André. Arqueologia brasileira. Brasília: Editora da UNB, 1992. 
TENóRIO, Maria Cristina (org.). Pré-bistória da Terra Brasilis. Rio de Janeiro: Editora UFRJ, 1999 .

Tesouros do Brasil - Livro do professor. São Paulo: La Fabbrica do Brasil, 2004.

\section{Education and preservation of archeological sites}

\section{ABSTRACT}

This paper is part of a monitory project developed through the class of Prehistoric, from History Graduation Course of Universidade Federal da Paraíba in the year of 2004, under the supervision of Prof. Ricardo Pinto de Medeiros, PhD. Its major purpose is to develop a methodological opportunity of patrimonial education, focused on the preservation of archeological patrimony. It aims students' recognition of these values, spreading their knowledge into more wide preservation consciousness, making them aware of History's importance in the construction of a reliable society, which will allow the future generations the access of knowledge in different ways, building up, therefore, a social identity. .

Key words: Patrimony, Archeology, Methodology, Patrimonial education 